\title{
Examining Drivers of Divergence in Recorded and Perceived Human-Carnivore Conflict Hotspots by Integrating Participatory and Ecological Data
}

\author{
Christine E. Wilkinson ${ }^{1 *}$, Justin S. Brashares ${ }^{1}$, Alice C. Bett ${ }^{2}$ and Maggi Kelly ${ }^{1}$ \\ ${ }^{1}$ Department of Environmental Science, Policy, and Management, University of California, Berkeley, Berkeley, CA, \\ United States, ${ }^{2}$ Kenya Wildlife Service, Nairobi, Kenya
}

\section{OPEN ACCESS}

Edited by:

Jenny Anne Glikman,

Instituto de Estudios Sociales

Avanzados (IESA), Spain

Reviewed by:

Eivin Røskaft,

Norwegian University of Science and

Technology, Norway

Guy Western

University of Oxford, United Kingdom

*Correspondence:

Christine E. Wilkinson

christine.wilkinson@berkeley.edu

Specialty section:

This article was submitted to

Human-Wildlife Dynamics,

a section of the journal

Frontiers in Conservation Science

Received: 17 March 2021

Accepted: 16 June 2021

Published: 20 July 2021

Citation:

Wilkinson CE, Brashares JS, Bett AC and Kelly M (2021) Examining Drivers

of Divergence in Recorded and Perceived Human-Carnivore Conflict Hotspots by Integrating Participatory and Ecological Data.

Front. Conserv. Sci. 2:681769. doi: 10.3389/fcosc.2021.681769
Human-carnivore conflict is a global challenge with complex and context-specific causes and consequences. While spatial analyses can use ecological principles to predict patterns of conflict, solutions to mitigate conflict must also be locally adaptable, sustainable, and culturally-sensitive. In Nakuru County, Kenya, rapid development and land subdivision have exacerbated conflict by isolating wildlife in protected areas that are increasingly adjacent to human settlements. In an effort to understand local perspectives on carnivore conflict, and to apply this information toward locally-based conservations actions, we conducted gender-stratified interviews and participatory mapping sessions with 378 people in 16 villages near two ecologically isolated protected areas in Kenya: Lake Nakuru National Park and Soysambu Conservancy. Specifically, we developed a method for associating interview responses and demographic information with spatial participatory data to examine how local perceptions of conflict compared to spatially-explicit records of livestock depredation in the region from 2010 to 2018. We mapped kernel densities of recorded and perceived risk of human-carnivore conflict and then tested for potential social and ecological predictors of divergences found between the two datasets. Mismatched hotspots of observed and perceived risk of conflict were correlated with several ecological and socioeconomic factors. Regions with higher NDVI exhibited more perceived conflict, while the opposite held true for verified conflict. Road density was positively correlated with both types of conflict, and both types of conflict increased closer to protected areas. Livestock ownership, visitation to Lake Nakuru National Park, if the participant's child walked to school, and male gender identity were associated with more perceived conflict reports. Education level and national park visitation were associated with more positive attitudes toward carnivores. Our results show that while observed and perceived conflict may ultimately be equally important for understanding and managing human-carnivore conflict, they may be driven by markedly different social and ecological processes. We suggest that integrating the spatially explicit experiences and perspectives of local communities with more traditional ecological methods is critical to identifying lasting and socially just forms of conflict mitigation.

Keywords: human-carnivore conflict, risk perceptions, conservation practice, participatory mapping, socioecological 


\section{INTRODUCTION}

Human-carnivore conflict (HCC) is a primary driver of large carnivore declines globally (Ripple et al., 2014) and creates a significant challenge to rural livelihoods in many areas (Muhly and Musiani, 2009). For example, in the United States, over $\$ 168$ million in livestock losses per year are attributed to depredation by carnivores (USDA Animal and Plant Health Inspection Service, 2020). Livelihood impacts of HCC are most pronounced in regions where carnivore populations remain viable or have recovered, and where marginal incomes place producers near poverty (Dickman et al., 2011). Along with affecting livelihoods, human-wildlife conflict is known to have a number of indirect social and emotional impacts on affected communities, such as diminished psychological well-being and food insecurity (Barua et al., 2013). Conflicts between people and carnivores are exacerbated by a combination of sociopolitical factors (e.g., regional livelihoods, poverty, global wildlife policies; Treves and Karanth, 2003) and local histories of people's relationships with wildlife (e.g., Megaze et al., 2017), as well as increased development that has intensified habitat fragmentation and human-wildlife interactions (Were et al., 2013; Weldemichel and Lein, 2019). Thus, human-carnivore conflicts comprise impacts associated with interactions between carnivores and people, along with the human-human relationships underlying and influencing those interactions (Young et al., 2010; Redpath et al., 2015).

Conservation biologists lean heavily on an understanding of ecology when researching and managing human-carnivore conflict (Wilkinson et al., 2020). In recent years, there has been considerable momentum behind using ecological data in combination with innovative spatial tools for addressing conflict using scientific evidence (Miller, 2015; Miller and Schmitz, 2019). Predation risk mapping, for example, layers verified conflict events across ecological (e.g., habitat structure and productivity) and anthropogenic (e.g., human infrastructure and activity) variables in order to overcome HCC's inherent contextdependency, and to anticipate future carnivore conflict (e.g., Broekhuis et al., 2017). For instance, in arid ecosystems, conflict has been observed to increase in the rainy season when wildlife are not reliant on permanent water bodies and are able to disperse widely (Koziarski et al., 2016). Yet, in fenced arid ecosystems, wildlife transgressions of fences to exit protected areas may be higher in the dry season (Kesch et al., 2015), possibly because seasonal vegetation resources are more limited within fenced ecosystems than in unfenced ecosystems (Bartzke et al., 2018). Thus, predation on livestock and carnivore attacks on people in different regions with varying human development may exhibit measurable, context-specific, and spatially-explicit patterns across key ecological variables (Thorn et al., 2012). Additionally, anthropogenic structures and activity have altered wildlife behavior and ecology around the globe at numerous scales (Gaynor et al., 2018; McInturff et al., 2020), and may be consequential covariates when mapping carnivore conflicts with people. Risk mapping and other spatial methods have thus proven to be highly useful tools for quantifying correlates of verified conflict and employing ecological theory to create targeted mitigation strategies that address HCC (Melzheimer et al., 2020).

While global increases in HCC are regularly studied by examining the associations between ecological covariates and verified on-the-ground human-carnivore conflict reports, there is increasing understanding that the perception of risk held by local communities may more meaningfully predict their attitudes toward carnivores and their retaliatory or preventative actions (Dickman et al., 2014). Though interactions between wildlife and humans are situated within a broad range of social, institutional, and ecological landscapes, a key element of any human-carnivore interaction is human behavior (Lischka et al., 2018). Behavior of people when interacting with wildlife is, among other factors, driven by emotion, experience, and resulting attitudes and perceptions (Carter et al., 2012a), making human emotions and perceptions critical for understanding and resolving conflicts between people and carnivores.

A number of studies have acknowledged that perceptions of conflict can diverge from ecological findings and yet still provide tangible contributions to conservation efforts (Siex and Struhsaker, 1999; Dickman et al., 2014). Some of these have employed surveys to better understand the drivers of people's perceptions of conflict in space and time (e.g., Holmern et al., 2007). These studies and others suggest the most important observed social drivers of HCC perception, realization, and management outcomes among stakeholders are gender, education level, livestock ownership and adoption of tools for guarding livestock, and visitation and access to nearby protected areas (Tessema et al., 2010; Knopff et al., 2016; Mkonyi et al., 2017). For example, men and women may have different motivations, goals, and risk perceptions regarding human-wildlife conflict and management (Gore and Kahler, 2012), and women may bear disproportionate burdens of conflict due to gendered relations of space and identity (Ogra, 2008). Additionally, education level may influence attitudes toward wildlife and conservation (Akama et al., 1995; Holmern et al., 2007; Dressel et al., 2014; Megaze et al., 2017), and may also be an indicator of modernization, which is hypothesized to increase positive attitudes toward carnivore conservation (Bruskotter et al., 2017).

Livestock ownership also plays a potentially major role in perceptions of conflict since livestock owners are most likely to fear predation's impact on their livelihoods. These same stakeholders may be more likely to discuss conflict history or their perceptions of risk with neighbors (Kellert, 1985), which can contribute to spreading of perceived risks (Dickman et al., 2014). Relatedly, the adoption of common interventions designed to reduce carnivore conflicts (such as fladry, lights, noisemakers, etc.; van Eeden et al., 2018) may also impact people's perceptions of carnivores, conflict, and risk (Eklund et al., 2020). Number of livestock owned (Hemson et al., 2009) as well as number of children or family size (Khumalo and Yung, 2015), may also be indicators of financial precarity that influence conflict risk perceptions. Finally, national park visitation, as both a means of ecological education (e.g., Tomicevic et al., 2010) and connection to wildlife living on the landscape (e.g., through ecotourism; Waylen et al., 2009), may have the potential to affect 
community members' understanding of and thus reaction to carnivores (Espinosa and Jacobson, 2012; Mkonyi et al., 2017). These social factors can be as critical as ecological variables when understanding and predicting patterns of HCC across different landscapes.

While these and other socioeconomic factors help predict local perceptions of conflict, the application of information on perceptions to structure and implement programs HCC is rare (Lozano et al., 2019). Moreover, the participatory methodologies necessary to assess and apply human perceptions are scarce across human-wildlife conflict research (Gray et al., 2020). This is despite the known importance of considering spatial, ecological, and social variables together for long-term conflict mitigation (White et al., 2009), and the common acknowledgment that conservation conflicts are best managed when science and solutions are co-created with affected communities (Treves et al., 2009; Redpath et al., 2013). In fact, examples abound of cases where a lack of participatory and integrative approaches have contributed to ineffective, short-lived, and/or unjust solutions to conflict (Meguro and Inoue, 2011; Eklund et al., 2020). For targeted and effective outreach and management of HCC, we need to address this disconnect by working toward an understanding of how and why verified and perceived HCCs diverge (Dickman, 2010), as well as how conflict risk perceptions cluster spatially and are driven by various social and ecological factors (Bruskotter and Wilson, 2014).

Here, we sought to bridge this gap by using a unique combination of verified conflict reports and participatory perception data to answer the following questions: (1) How do verified and locally perceived carnivore conflict compare spatially?, (2) How are similarities and differences in the two datasets correlated with ecological variables and infrastructure?, and (3) Are there social predictors (e.g., demographics, livestock ownership, and attitudes toward carnivores) of the level and distribution of perceived carnivore conflict? We examined these questions in the region surrounding Lake Nakuru National Park and Soysambu Conservancy in the Rift Valley of Kenya. This location provided an ideal system for this study because of its high rate of human immigration and land subdivision, and the resulting close proximity of wildlife to people, human activities, and infrastructure (Kassilly et al., 2008; Mubea and Menz, 2012; Wilkinson et al., 2021). We predicted (1) that verified and perceived conflict would exhibit observable spatial differences, and (2) that these disparities would be driven by a variety of ecological factors, such as season, vegetation, road density, and distance to protected areas, as well as social factors, such as participant education level, gender, livestock ownership and activities, and national park visitation (Table $\mathbf{1}$ ).

\section{METHODS}

\section{Study Site}

We conducted our study in Nakuru County, in the Rift Valley, southwest Kenya (Figure 1) from June 2018 to March 2019. The study area $\left(\sim 500 \mathrm{~km}^{2}, 0^{\circ} 26^{\prime} \mathrm{S}, 36^{\circ} 1^{\prime} \mathrm{E}\right)$ includes two major wildlife protected areas: Lake Nakuru National Park (LNNP, $188 \mathrm{~km}^{2}$ ), which is one of two fully fenced national parks in
Kenya, and Soysambu Conservancy $\left(190 \mathrm{~km}^{2}\right)$, which is semifenced and functions simultaneously as a wildlife conservancy and a livestock ranch with over 10,000 cattle, sheep, and goats. The two large alkaline lakes in the region, Lake Nakuru and Lake Elmenteita, are designated UNESCO World Heritage sites. The region supports many species of large mammals, including threatened and endangered species such as black rhinoceros (Diceros bicornis) and Rothschild's giraffe (Giraffa camelopardalis rothschildi); large carnivore species, such as African lion (Panthera leo), spotted hyena (Crocuta crocuta), and leopard (Panthera pardus); and several mesocarnivore species, such as serval (Leptailurus serval) and black-backed jackal (Lupulella mesomelas). Many carnivore populations in the region (both inside and outside of protected areas) are stable or increasing despite heavy historical persecution (Ogutu et al., 2017).

Outside of protected areas, the Nakuru-Elmenteita watershed is home to dense human populations, with considerable immigration into the region. Small-scale agriculture and pastoralism, as well as increased urbanization, are common in the settled areas surrounding LNNP and Soysambu Conservancy, and there is a mix of ethnic representation (mostly Kikuyu, Kalenjin, and Maasai). Nakuru town, which is directly adjacent to the northern border of LNNP, is home to an estimated 570,674 people (Kenya National Bureau of Statistics, 2019) and is considered to be one of the fastest growing cities in East Africa. In many places throughout the study area, human settlements directly about the conservancy and park boundaries.

\section{Participatory Data Data Collection}

In order to gather community perspectives on carnivores and conflict, we selected 16 sub-villages, within 5 broader village areas, located within $5 \mathrm{~km}$ of the protected area boundaries (Figure 1). The sample comprised representation from every rural village with lands adjacent to the two protected areas, while excluding urban areas. Though participatory mapping is subject to inherent logistical, access, and scalability limitations (Brown, 2012), we addressed these challenges in a number of ways through iterative pre-testing and sampling considerations. Because the study area was large and many of the households were unmapped, we used semi-random heterogeneity sampling (Blankertz, 1998) to identify 378 participants (180 women, 198 men) for participatory mapping and interview sessions. Participants were informed (a) they could leave mapping and interview sessions at any time, (b) that participation in the exercise was not mandatory, and (c) that compensation was not provided. To reduce bias in responses, participants were informed that the interviewers and facilitators were students, and that the students held no direct authority in addressing human-wildlife conflict issues.

For each participatory mapping session, we aimed for 12 participants, with no more than 6 participants drawing on a single map (for legibility purposes). However, this wasn't always feasible, as the mapping sessions were popular and occasionally drew crowds. Thus, in a few circumstances, up to 8 participants drew on a single map. Mapping sessions were gender-stratified, 
TABLE 1 | Hypotheses related to verified conflict, perceived conflict, and attitudes toward carnivores.

\begin{tabular}{|c|c|c|}
\hline Variable & Hypotheses & References \\
\hline Education level & $\begin{array}{l}\text { Increasing education level is correlated with } \\
\text { 1) more positive attitudes toward carnivores conservation, and } \\
\text { 2) fewer perceived conflict reports. }\end{array}$ & $\begin{array}{l}\text { Akama et al., 1995; Holmern et al., 2007; } \\
\text { Dressel et al., 2014; Bruskotter et al., } \\
\text { 2017; Megaze et al., } 2017\end{array}$ \\
\hline $\begin{array}{l}\text { National park visitation by } \\
\text { participant or child }\end{array}$ & $\begin{array}{l}\text { Participants who have visited the national park, or whose children have visited the } \\
\text { national park are more likely to } \\
\text { 1) have positive attitudes toward carnivores, and } \\
\text { 2) report fewer perceived conflicts. }\end{array}$ & $\begin{array}{l}\text { Tomicevic et al., 2010; Espinosa and } \\
\text { Jacobson, 2012; Hausmann et al., 2016; } \\
\text { Mkonyi et al., } 2017\end{array}$ \\
\hline $\begin{array}{l}\text { Active nighttime livestock } \\
\text { guarding }\end{array}$ & $\begin{array}{l}\text { Livestock owners who employ tools to actively guard their livestock at night are more } \\
\text { likely to } \\
\text { 1) have positive attitudes toward carnivores, and } \\
\text { 2) report fewer perceived conflicts. }\end{array}$ & Holmern et al., 2007; Rust et al., 2013 \\
\hline Perceived threats to children & $\begin{array}{l}\text { Participants who believe carnivores pose a threat to children on their way to school } \\
\text { are more likely to } \\
\text { 1) have negative attitudes toward carnivores, and } \\
\text { 2) report more perceived conflicts. }\end{array}$ & $\begin{array}{l}\text { Bruskotter and Wilson, 2014; Bruskotter } \\
\text { et al., } 2017\end{array}$ \\
\hline Number of children & $\begin{array}{l}\text { Increasing number of children is correlated with } \\
\text { 1) negative attitudes toward carnivores, and } \\
\text { 2) more perceived conflict reports. }\end{array}$ & $\begin{array}{l}\text { Khumalo and Yung, 2015; Bruskotter } \\
\text { et al., } 2017\end{array}$ \\
\hline Gender & $\begin{array}{l}\text { 1) Women are more likely to have negative attitudes toward carnivores. } \\
\text { 2) Men are more likely to report more perceived conflicts. }\end{array}$ & Ogra, 2008; Gore and Kahler, 2012 \\
\hline Livestock ownership & $\begin{array}{l}\text { 1) Livestock owners are more likely to } \\
\text { a. have negative attitudes toward carnivores, and } \\
\text { b. to report more perceived conflicts. } \\
\text { 2) These effects are stronger with increasing number of livestock owned. }\end{array}$ & $\begin{array}{l}\text { Kellert, 1985; Hemson et al., 2009; } \\
\text { Dorresteijn et al., 2014; Dressel et al., } \\
2014\end{array}$ \\
\hline Season & $\begin{array}{l}\text { 1) Verified conflict increases during the rainy season. } \\
\text { 2) Perceived conflict shows no difference between seasons. }\end{array}$ & Koziarski et al., 2016; Bartzke et al., 2018 \\
\hline Vegetation greenness (NDVI) & 1) NDVI is positively correlated with both perceived and verified carnivore conflict. & $\begin{array}{l}\text { Thorn et al., 2012; Koziarski et al., 2016; } \\
\text { Bartzke et al., 2018; Ugarte et al., } 2019\end{array}$ \\
\hline $\begin{array}{l}\text { Road density (as a proxy for } \\
\text { human population) }\end{array}$ & 1) Road density is positively correlated with both perceived and verified conflict. & $\begin{array}{l}\text { Treves and Karanth, 2003; Ugarte et al., } \\
2019\end{array}$ \\
\hline Distance to protected area & $\begin{array}{l}\text { 1) Distance protected area is negatively correlated with both perceived and verified } \\
\text { conflict, with a stronger effect for verified conflict. }\end{array}$ & $\begin{array}{l}\text { Mkonyi et al., 2017; Ugarte et al., 2019; } \\
\text { Weldemichel and Lein, 2019; Gray et al., } \\
2020\end{array}$ \\
\hline
\end{tabular}

with men and women gathering on different days to encourage open conversation and a broad range of perspectives (Pfeiffer and Butz, 2005). A total of 322 maps were drawn across all participatory mapping questions and sessions.

Each interviewee's session began with a short $(\sim 10 \mathrm{~min})$ one-on-one interview, with a Kenyan master's student serving as an interviewer, using the application Open Data Kit (ODK; https://getodk.org/), carried out on Android devices (Motorola Moto E). Interviews were conducted in English or Kiswahili, depending on the interviewee's preference. Information gathered included demographic data, risk perceptions about carnivores, attitudes toward carnivores and carnivore conservation, livestock ownership, experience with carnivore-livestock conflict, educational experience, national park visitation, and employment (Appendix 1), with a combination of multiple choice, check all that apply, numerical, and open-ended questions. Prior to the interview, each participant was assigned a unique pen color for the day. During the initial interview, a photo was taken of their pen within the ODK application. This allowed us to associate a participant's spatial data with their interview data while maintaining anonymity.
For the participatory mapping portion of the sessions, paper maps were developed and printed using Field Papers (www.FieldPapers.org). Field Papers is an open source tool to print basemaps that can be annotated in the field and then scanned, allowing annotation to be digitized into a GIS database. During the sessions, participants were first given a minimum of 15 min of map orientation, though these orientation exercises and conversations often lasted longer than $30 \mathrm{~min}$. Participants were encouraged to teach one another by using laminated, highly detailed atlases of the region, and finding locations of interest to the community such as the national park, particular intersections, Nakuru town, and village centers. We asked participants to use the assigned pens and paper maps we provided to draw their answers to 24 general questions regarding places of importance, livestock predation, carnivore presence, desired carnivore conservation and movement, risk perceptions regarding carnivores, and other factors (Appendix 1). For each question on each map, a unique (to that map) symbol (falling into the categories of point, line, or polygon) was requested. Participants were encouraged to draw on top of one another's symbols as needed. 


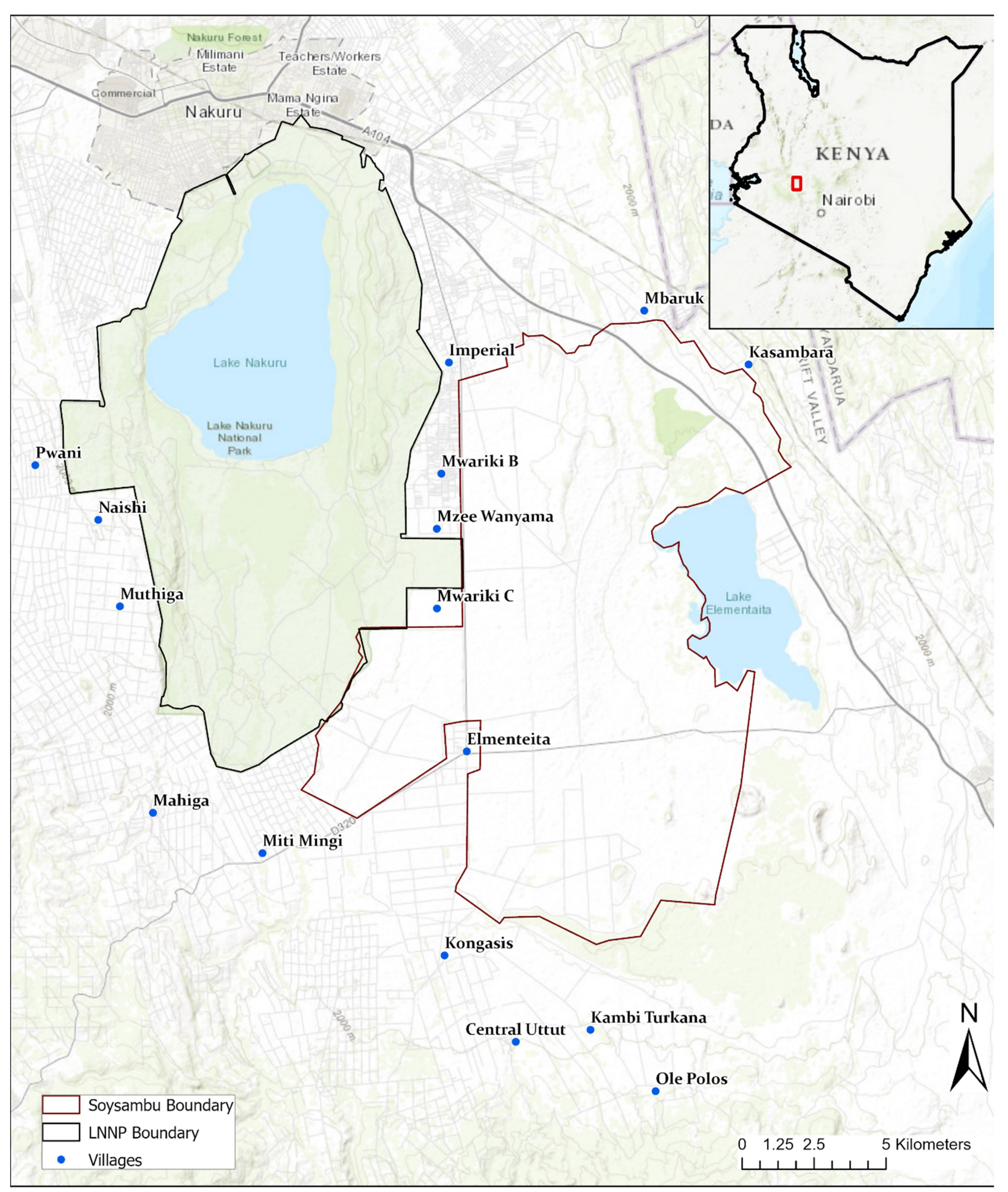

FIGURE 1 | Map of the study area, including villages surveyed. 


\section{Participatory Data Preparation}

To digitize maps, participatory maps were photographed, and a QR code allowed the map images to be georeferenced directly using FieldPapers.org. Georeferenced map images were then uploaded into ArcGIS Pro (Version 2.5) in order to trace each question's spatial responses (points, lines or polygons) into GIS layers, with each layer representing the collected answers to one question. During the digitization process, pen colors on each session's maps were again cross-referenced with photographs of pen colors that had been automatically labeled with each interview's unique identification number. These identification numbers were assigned to each feature in each layer's attribute table. Interview data were then joined with attribute tables for each layer, and each question's layers were subsequently merged into a single master layer that included data from all sessions for that question.

\section{Verified Conflict Data}

Human-carnivore conflict (HCC) data for 2008-2018 were provided by the Kenya Wildlife Service. The dataset contains HCC incidents (such as carnivore attacks on livestock and threats to people) reported to the Nakuru Community Wildlife Service (CWS) station. The station houses trained rangers who respond to conflict issues and also undertake community outreach around the park and adjacent localities within the county. Conflict cases are reported by the local community through a dedicated telephone hotline or the institutional call center, both of which are open $24 \mathrm{~h}$ a day. Once a conflict report is received at the station, a CWS team is dispatched to verify. The details of the nature of each conflict are collected by the rangers and later recorded in an occurrence book. The information collected includes the date, location name, conflict species, the nature of the conflict, and the management action taken. Data recorded in the occurrence book are later entered into a database at the station. We obtained these verified conflict data from the main human-wildlife conflict database and georeferenced each record to the approximate village or sub-village level using landmarks and location names provided in the original dataset. While this dataset consisted of historical records of conflict which were initially collected solely for monitoring purposes (see Easterday et al., 2018), the data were cleaned and georeferenced points were iteratively verified with Kenya Wildlife Service staff prior to analysis.

\section{Spatial Explanatory Variables for Conflict Reports}

The ecological and anthropogenic spatial covariates that we tested as predictors of conflict reports included distance to protected area, road density (kernel density, per $\mathrm{km}^{2}$ ), mean vegetation greenness (as measured by NDVI- normalized difference vegetation index, via Landsat 8, for 2018), and slope (via Shuttle Radar Topography Mission, $30 \mathrm{~m}$ ).

\section{Data Analysis}

\section{Summary and Comparison of Verified and Perceived Conflict}

To determine spatial differences between the verified and perceived datasets, we used ArcGIS Pro to conduct kernel density estimations (KDE) for the entire verified conflict and perceived conflict datasets, respectively. From the KDE analyses ( search radius $=3 \mathrm{~km}$ ) we created difference maps comparing the verified and perceived datasets across all stratifications by subtracting the verified conflict KDE from the perceived conflict KDE. We thresholded difference maps to the upper and lower quantiles to determine areas of highest disagreement among the two datasets, and conducted generalized linear regressions to assess perceived and verified conflict density in relation to distance to protected area, road density, NDVI, and slope.

\section{Correlates of Local Clustering of Perceived Conflict}

In order to determine whether people with positive attitudes toward carnivores and who guard their livestock nonetheless exhibited significant clustering in their perceived carnivore conflict reports, we first used global logistic regressions to identify predictors (Supplementary Table 1) of (1) attitudes toward carnivores and (2) nighttime livestock guarding behavior. We then employed a geographically weighted logistic regression (GWLR; Brunsdon et al., 1996) to test for local clustering. The initial regressions revealed a best-supported model (AUC = 0.805 ) that included the following variables to retain for GWLR: cow ownership, sheep or goat (hereafter shoat) ownership, whether the participant collected water in the evening (i.e., landscape traversal at night), number of reasons reported for hyenas to be conserved, belief that hyenas have access to too few wild prey, and perceptions of carnivore-related threats to children on their way to school (Table 2).

\section{Trends in Verified Conflict Reports}

We used linear regression to test for trends in HCC reports over time for each carnivore species, for each livestock species and for humans, and for all carnivore species in aggregate using $R$ (R Core Team, 2018). For all non-spatial analyses, verified conflict data from 2013 were excluded because reports were only recorded for 1 month of that year.

\section{Predictors of Perceived Conflict/Risk and Attitudes Toward Carnivores}

To determine correlates of perceptions, we assessed the correlates of two variables: perceived carnivore conflict and attitudes toward spotted hyenas. As a widely reviled carnivore species in sub-Saharan Africa (Glickman, 1995), and as one of the most populous and visible carnivores in this region (Wilkinson et al., 2021), spotted hyenas served as the best proxy for examining what drives differences in attitudes toward conflictprone carnivores among Nakuru County residents. Thus, the main proxy for attitudes utilized in this study was "Do you think it is important to conserve the spotted hyena?" Pair-wise analyses were conducted for all relevant explanatory variables (age, education, national park visitation by participant, national park visitation by participant's child, livestock ownership, whether participant actively guards livestock at night, number of livestock owned). To determine whether perceived carnivore conflict or attitudes could be predicted using these variables, a logistic regression was then run for each dependent variable across all explanatory variables. After eliminating any collinear variables using the vif function, we used the dredge function in the MuMin 
TABLE 2 | Variables retained in best-performing model of predictors of attitudes toward spotted hyena conservation (AUC = 0.805).

\begin{tabular}{|c|c|c|c|c|}
\hline Variable & $\beta$ & SE & z-value & $p$-value \\
\hline Has experienced an attack on their cattle* & -1.758 & 0.945 & -1.86 & 0.063 \\
\hline "Hyenas are attacking livestock due to food shortage" & 0.793 & 0.29 & 2.731 & 0.006 \\
\hline Time of day participant leaves their home for food & 0.157 & 0.092 & 1.712 & 0.086 \\
\hline Fears carnivores on child's way to school* & 0.68 & 0.288 & 2.358 & 0.018 \\
\hline Visited LNNP* & 0.738 & 0.289 & 2.55 & 0.011 \\
\hline Primary occupation: farmer/herder & -0.682 & 0.302 & -2.255 & 0.024 \\
\hline
\end{tabular}

"Y/N questions: "No" is the reference variable.

package in $R$ to conduct model selection, and retained model variables within 2 delta AIC of the top model for model averaging (Burnham and Anderson, 2002). To test the robustness of the top model, we bootstrapped a calculation of the area under the receiver operating characteristics curve (AUC; Pearce and Ferrier, 2000). We randomly split the data into $20 \%$ testing and $80 \%$ training data, and calculated AUC using the performance function in the ROCR package. AUC values below 0.7 were considered poor, values between 0.7 and 0.8 were considered acceptable, and values $>0.8$ were considered good or excellent (Hosmer and Lemeshow, 2000).

Finally, to assess underlying values and beliefs that may lead to positive or negative attitudes toward carnivores, we conducted descriptive statistics and pairwise analyses of responses to followup questions in which we had asked people to describe why they did or did not believe spotted hyena conservation was important (see Appendix 1).

\section{RESULTS}

\section{Spatial Patterns of Verified and Perceived Carnivore Conflict Overall Patterns and Correlates}

Verified and perceived conflict reports exhibited marked differences in spatial distribution and density. Kernel density estimates revealed a maximum of 3.34 verified and 3.44 perceived conflict reports per $\mathrm{km}^{2}$ within the study area (Figures $2 \mathrm{~A}, \mathbf{B}$ ). The difference map $\left(\mathrm{KDE}_{\text {perceived }}-\mathrm{KDE}_{\mathrm{verfied}}\right)$ showed a maximum of 3.02 , and a minimum of -3.44 , with a mean difference of 0.044 , meaning differences in the mapped reports across the study area skewed slightly toward perceived conflict. However, the minimum indicated a region on the map where there were no perceived conflict reports at all (Figure 2C).

KDE analyses exhibited $198.88 \mathrm{~km}^{2}$ of high divergence (quantified as first [ -3.44 to -0.444$]$ and eighth [0.709-3.02] quantiles of difference) between the two datasets: $87.02 \mathrm{~km}^{2}$ ( $\sim 9.8 \%$ of the KDE study extent) skewing toward perceived conflict, and $111.856 \mathrm{~km}^{2}(\sim 12.6 \%$ of the study area) skewing toward verified conflict (Figure 2A). Within these areas of maximum divergence, mean NDVI for the lower quantile (i.e., areas skewed toward verified conflict) was $0.283(\sigma=0.038)$, while mean NDVI for areas skewed toward perceived conflict was $0.316(\sigma=0.015)$. NDVI was positively correlated with perceived conflict kernel density $(\beta=0.477, p<0.01)$, and negatively correlated with verified conflict kernel density $(\beta=$ $-0.413, p<0.01)$. Mean road density within areas of maximum divergence was $2.46(\sigma=1.113)$ for areas skewed toward perceived conflict, and $2.23(\sigma=0.341)$ for areas skewed toward verified conflict. Road density was positively correlated with both perceived $(\beta=0.115, p<0.001)$ and verified $(\beta=0.103, p<$ $0.001)$ conflict density. Distance to protected area was strongly negatively correlated with perceived $(\beta=-13.327, p<0.001)$ and verified $(\beta=-13.794, p<0.001)$ conflict, while slope showed a slight negative correlation with both perceived ( $\beta=$ $-0.009, p<0.05)$ and verified $(\beta=-0.016, p<0.001)$ conflict.

\section{Correlates of Local Clustering of Perceived Conflict}

Those engaged in nighttime guarding of cattle did not differ from others in their spatial perceptions of HCC hotspots (Figure 3A), but geographically weighted logistic regression revealed local clusters (Figures 3B,C). GWLR results indicated that perceived carnivore-related threats to children and beliefs that wild prey was scarce correlated with local clusters of perceived conflict that were reported despite guarding behavior (Figures 3B,C).

Those who reported positive attitudes toward spotted hyenas similarly did not exhibit marked clustering in their perceptions of HCC hotspots. Similarly to the guarding behavior results, GWLR revealed that park visitation, perceptions of carnivore-related threats to children, and nighttime livestock guarding correlated with varying local clusters of perceived conflict reports in relation to attitudes (Figure 4).

\section{Trends in Verified Conflict Reports}

There was an upward, but non-significant, pattern in overall verified conflict reports over time (Figure 5A). However, carnivore species exhibited different trends over time: there was a slight downward trend in proportion of conflicts attributed to leopards $(\beta=-0.0399, p<0.01)$, an upward trend in the proportion of conflicts attributed to servals $(\beta=0.0189, p$ $<0.01$ ), as well as non-significant upward trends in proportion of conflicts attributed to spotted hyena $(\beta=0.0091, p=$ 0.428 ) and lion $(\beta=0.0119, p=0.331)$ (Figure 5B). As far as livestock attacked, verified conflict reports concerning sheep $(\beta=-0.0145, p<0.05)$, and dogs $(\beta=-0.0129, p<0.05)$ decreased over time (Figure 5C). A higher number of verified conflict reports were reported during the dry season, but this result was non-significant (Supplementary Figure 1). 


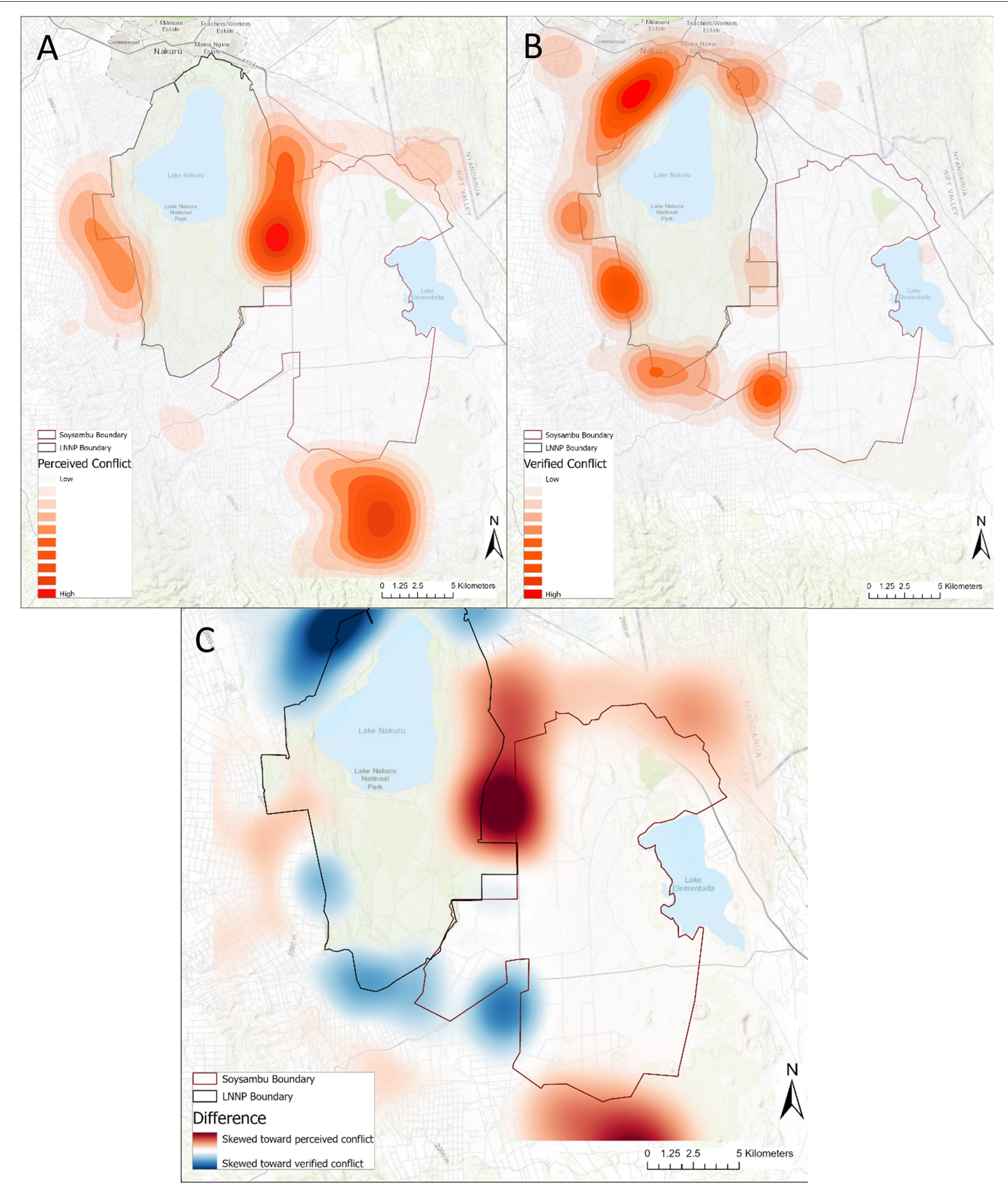

FIGURE 2 | Kernel density estimates of (A) perceived and (B) verified conflict reports, and (C) difference map showing KDE perceived $^{-} \mathrm{KDE}_{\mathrm{verfied}}$. 


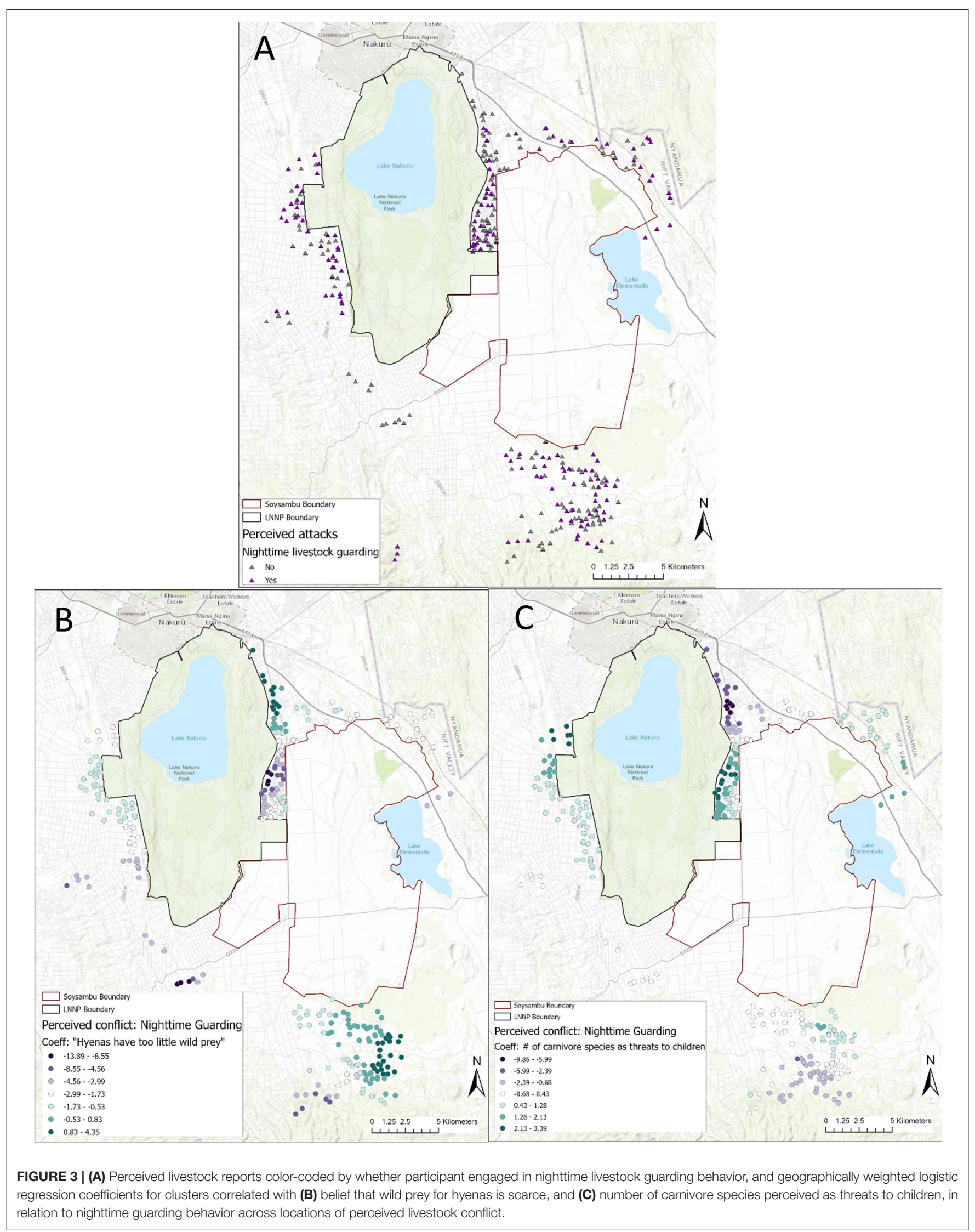




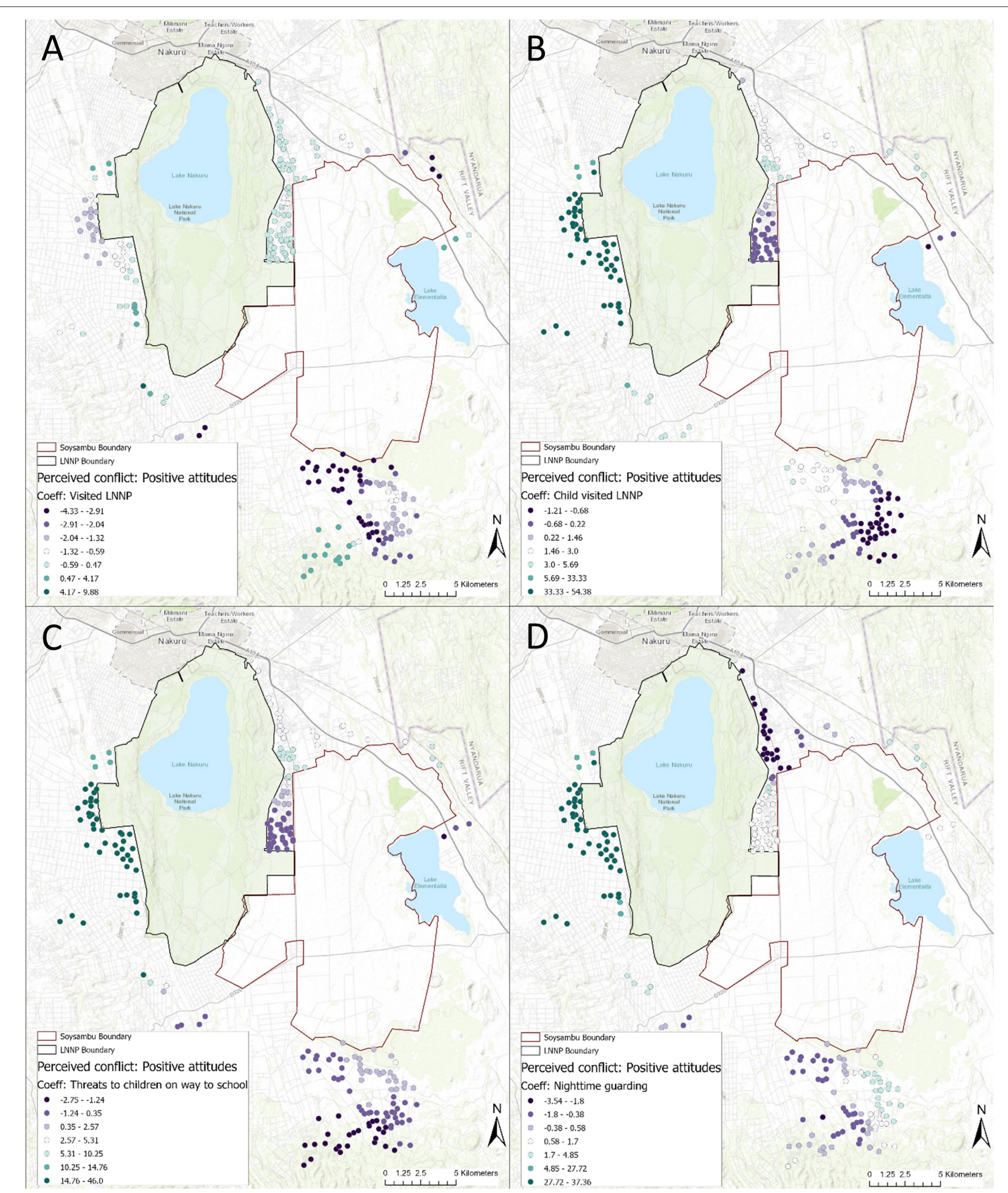

FIGURE 4 | Geographically weighted logistic regression coefficients for clusters correlated with (A) national park visitation by participant, (B) national park visitation by participant's child(ren), (C) whether participant perceives carnivore-related threats to their children on their way to school, and (D) nighttime livestock guarding, in relation to attitudes toward carnivores across locations of perceived livestock predation. 
A

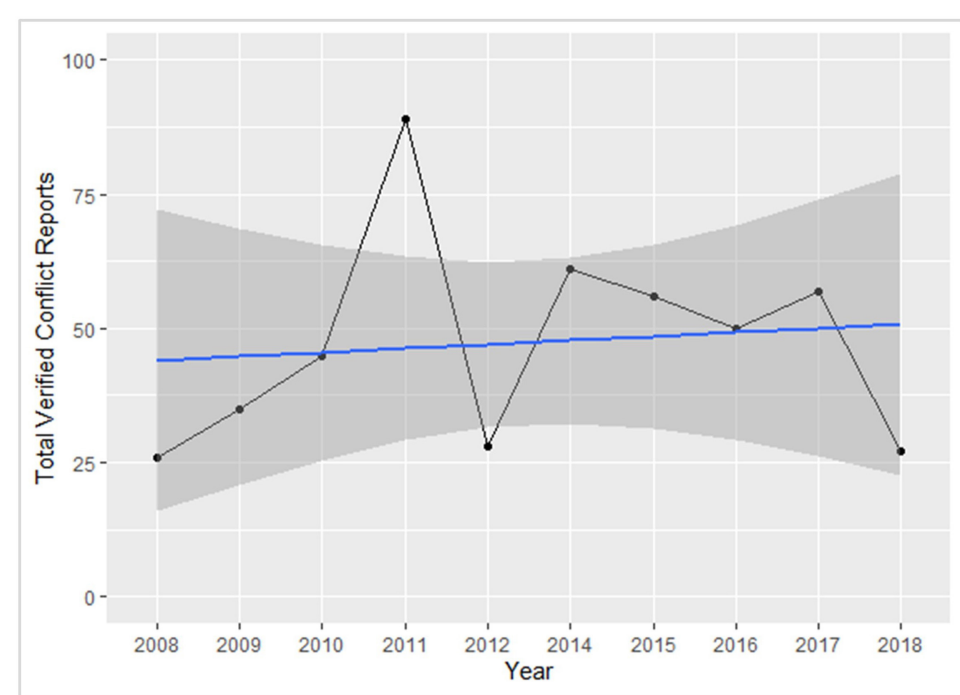

B

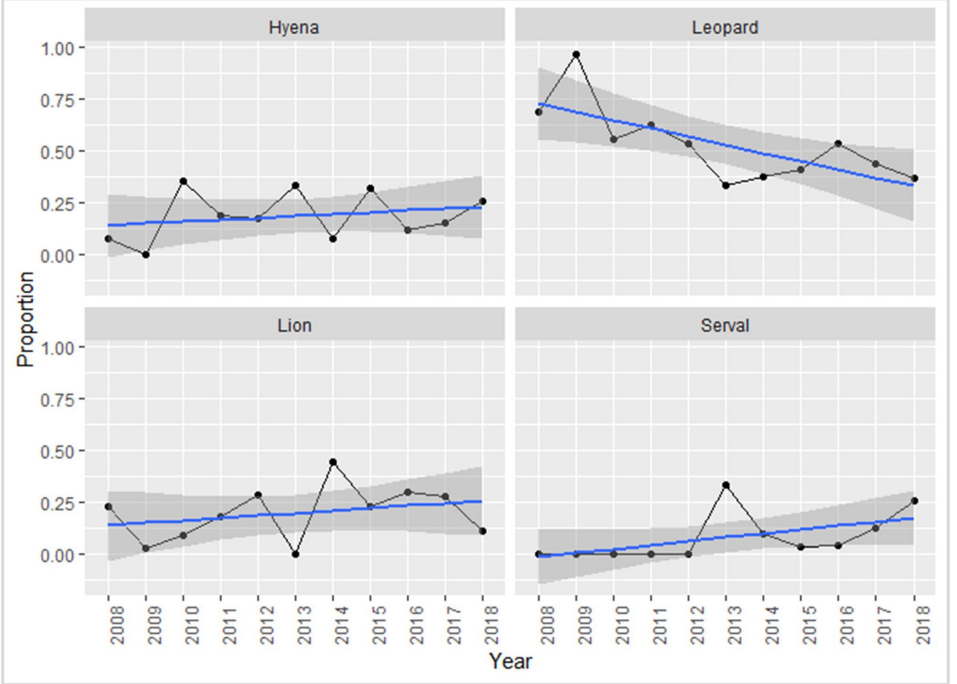

C

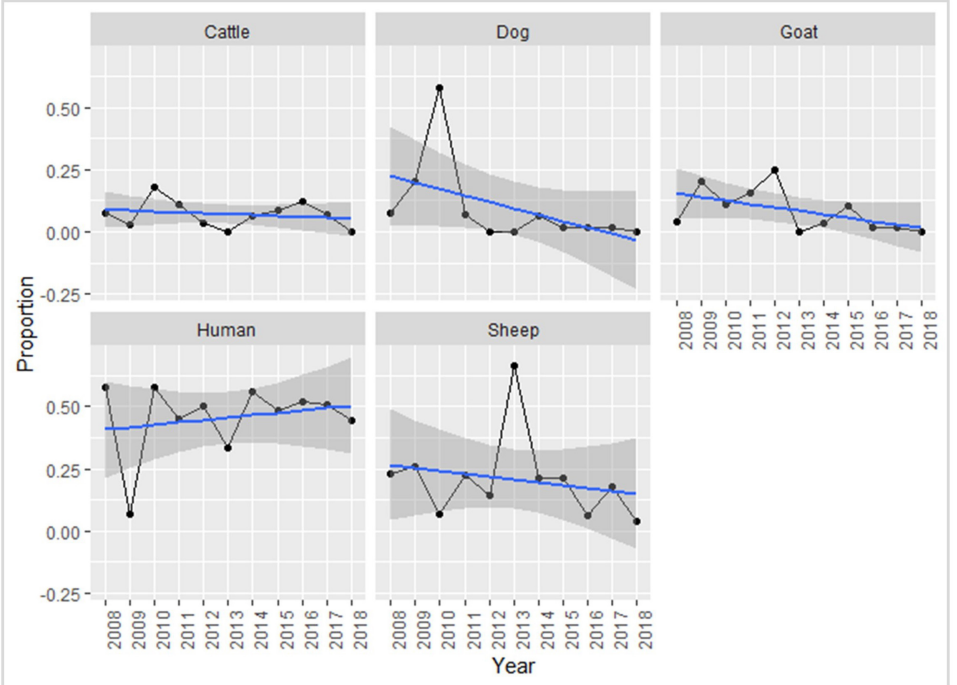

FIGURE 5 | (A) Total verified conflict reports, (B) relative proportions of carnivore species reported over time, and (C) relative proportions of reports regarding threats to livestock or humans over time for Nakuru County. 
TABLE 3 | Statistically significant results of pairwise analyses examining predictors of perceived conflict reports.

\begin{tabular}{|c|c|c|c|c|}
\hline \multicolumn{5}{|c|}{ Perceived livestock attacks } \\
\hline \multicolumn{5}{|l|}{ Gender } \\
\hline Male & 1.725 & 0.001 & & Wilcoxon signed-rank \\
\hline Female & 1.13 & & & \\
\hline \multicolumn{5}{|l|}{ Visited LNNP } \\
\hline No & 0.82 & & & \\
\hline Education level & & 0.002 & 0.157 & Im \\
\hline \multicolumn{5}{|c|}{ Nighttime livestock guarding } \\
\hline & 1.289 & 0.064 & & One-way ANOVA \\
\hline & 1.484 & & & \\
\hline
\end{tabular}

\section{Predictors of Perceived Conflict/Risk and Attitudes Toward Carnivores}

Gender and national park visitation were the strongest predictors of the number of conflict reports (Table 3). Pairwise analyses showed that livestock owners who have more children were less likely to indicate more perceived livestock attacks on the map ( $\beta$ $=-0.101, p<0.05)$. Livestock owners with a higher education level were slightly more likely to report more conflict events on the map ( $\beta=0.157, p<0.01)$. On average, men reported higher numbers $(\overline{\mathrm{x}}=1.725)$ of perceived livestock attacks than women reported $(\overline{\mathrm{x}}=1.13, p=0.001)$. Unexpectedly, participants who had visited the national park were likely to report more perceived livestock attacks $(\overline{\mathrm{x}}=1.41)$ than participants who had not visited the park $(\overline{\mathrm{x}}=0.82, p=0.001)$. If a participant guarded their livestock at night, they reported slightly fewer livestock attacks ( $\overline{\mathrm{x}}$ $=1.289$ livestock attacks) than those who did not actively guard their livestock at night $(\overline{\mathrm{x}}=1.484)$, though the result showed low significance $(p=0.064)$.

When asked whether they feared risks to children from carnivores on their children's way to school, people who actively guard their livestock at night $\left(X^{2}=6.1274, p<0.05\right)$ or whose children walk to school [which is $86.2 \%$ of participants who had children] $\left(X^{2}=4.3355, p<0.05\right)$ were more likely to perceive risks to children. Carnivore species feared as risks to children were spotted hyena (34.4\% of participants), leopard (33.9\%), lion (27.5\%), and black-backed jackal (20.1\%).

\section{Attitudes Toward Carnivore Conservation Main Predictors of Attitudes}

Education, national park visitation, and whether participants guarded their livestock at night were the strongest predictors of attitudes toward carnivore conservation (Table 4), with $70.8 \%$ of participants believing that spotted hyenas should be conserved. According to pairwise analyses on attitudes toward spotted hyena conservation (as a proxy for carnivore conservation more generally), if a participant had visited the national park, they were more likely to have positive views of hyena conservation than if they had not visited the park (Fisher test, two-sided, $p$ $<0.001$; Figure 6A). Additionally, if a participant's child had visited the park, they were more likely to have positive views of hyena conservation (Fisher test, two-sided, $p=0.001$ ). This was true despite 82 participants in the latter group (i.e., $44 \%$ of the 186 participants with children who have visited the national park) never having visited the national park themselves. Attitudes toward hyena conservation were also more likely to be positive with increasing education level $(\beta=0.3241, p<0.001$; Figure 6B), and for livestock-owning participants who actively guard their livestock at night (Fisher test, two-sided, $p<0.01$ ).

If a participant owned any species of livestock, they were less likely to believe hyenas should be conserved (Fisher test, two sided, $p=0.01)$. Participants who self-identified as farmers and herders for their primary livelihood (Fisher test, two sided, $p<$ 0.01 ), or said their children face risks from carnivores on the way to school (Fisher test, two sided, $p=0.01$ ), were also considerably less likely to report positive attitudes toward hyena conservation. Participants who owned at least one shoat in particular were significantly less likely to believe hyenas should be conserved ( $\beta$ $=-0.322, p<0.01)$, and cattle owners followed the same pattern $(\beta=-0.5011, p<0.01)$.

\section{Reasons for Positive and Negative Attitudes Toward Hyena Conservation}

Participants who said it was important for spotted hyenas to be conserved believed this due to ecotourism (83.3\%), ecological reasons (43.2\%), cultural reasons $(15.2 \%)$, or other reasons such as for children to view in the future ("For the next generation"), or because hyenas were created by God ("They are God's creatures"). Participants who said it was not important for spotted hyenas to be conserved largely believed this due to the species' role in livestock attacks (89\%), attacks on people (38\%), or belief that hyenas are a bad omen (11\%).

Of participants who supported hyena conservation, if the participant was older $(\beta=-0.2003, p<0.01)$, owned higher numbers of cattle $(\beta=-0.3439, p<0.05)$, or owned higher numbers of shoats $(\beta=-0.2372, p<0.05)$, they were less likely to say that ecotourism money was the reason to conserve spotted hyenas. Women $\left(X^{2}=4.1778, \mathrm{df}=1, p<0.05\right)$, participants with higher education levels $(\beta=0.2279, p<0.001)$, and participants 
TABLE 4 | Statistically significant results of pairwise analyses examining predictors of attitudes toward spotted hyena conservation.

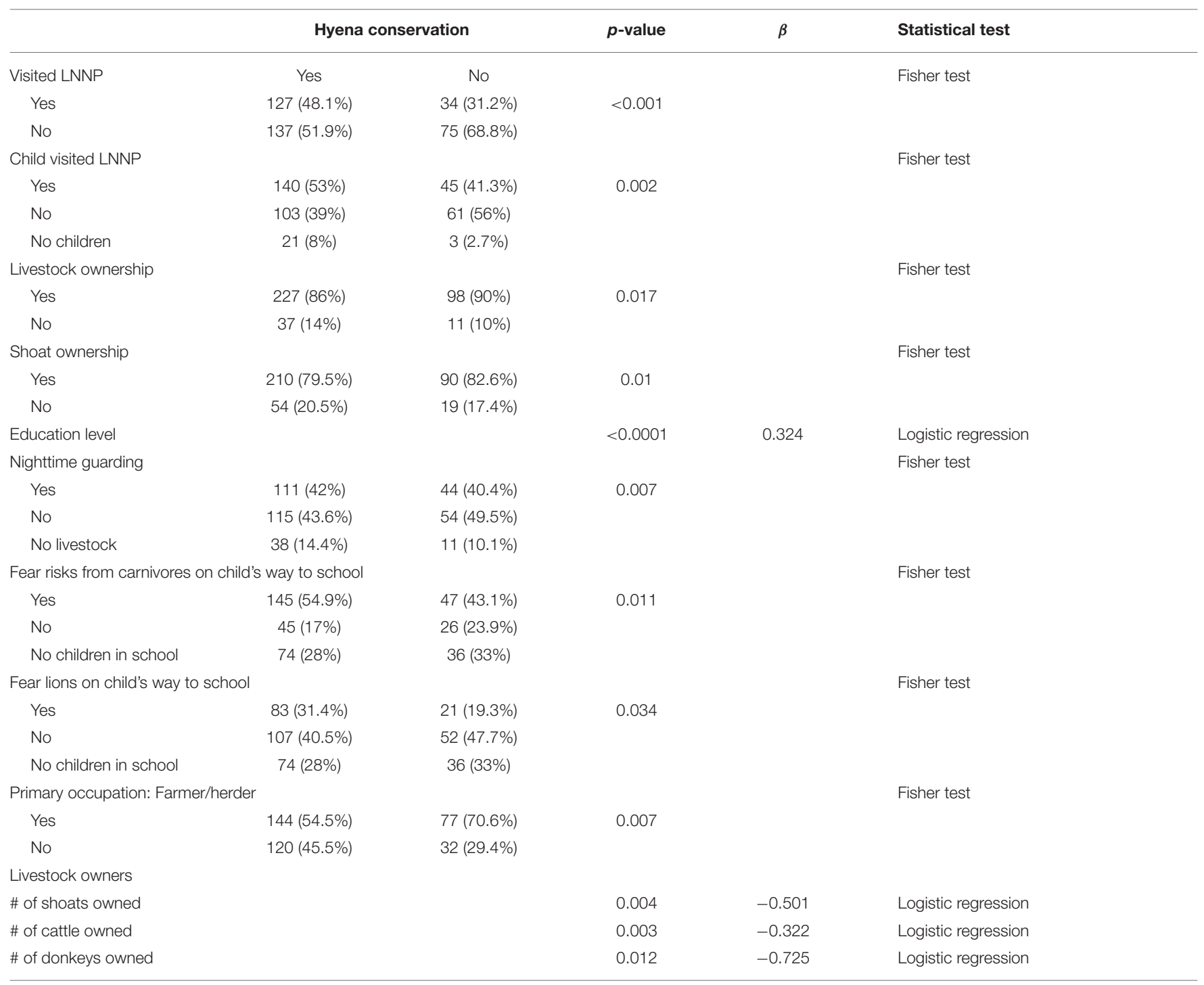

whose children had visited the national park $\left(X^{2}=7.9898, \mathrm{df}=\right.$ $2, p<0.05)$ were more likely to report ecotourism money as a reason to conserve spotted hyenas.

Meanwhile, participants who had visited the national park were more likely to report ecological reasons to justify why it was important to conserve spotted hyenas $\left(X^{2}=4.637, \mathrm{df}=1\right.$, $p<0.05)$, as were participants with higher education levels $(\beta=$ $0.1351, p<0.05)$.

\section{DISCUSSION}

This study used a uniquely interdisciplinary dataset to advance our understanding of the social and ecological drivers of humanwildlife conflict. Our analyses provided three main conclusions: (1) verified and perceived conflict exhibit quantifiably different spatial patterns, (2) information from verified conflict reports may be tied to anthropogenic ecosystem changes, and (3) park visitation, education level, and gender may be strong predictors of risk perceptions and attitudes toward carnivores, and can thus serve as conservation targets or mechanisms for managers in conjunction with spatial information.

\section{Mismatch in Perceived and Verified Conflict}

There were clear spatial differences between the perceived and verified conflict datasets. Areas of mismatch between verified and perceived conflict density comprised $\sim 20 \%$ of the conflict study area, with clear local regions where conflict skewed toward perceived or skewed toward verified. Though the effect was slim, NDVI was positively correlated with perceived conflict and negatively with verified conflict. This could be due to overinflation of perceived conflict in highly vegetated regions that 


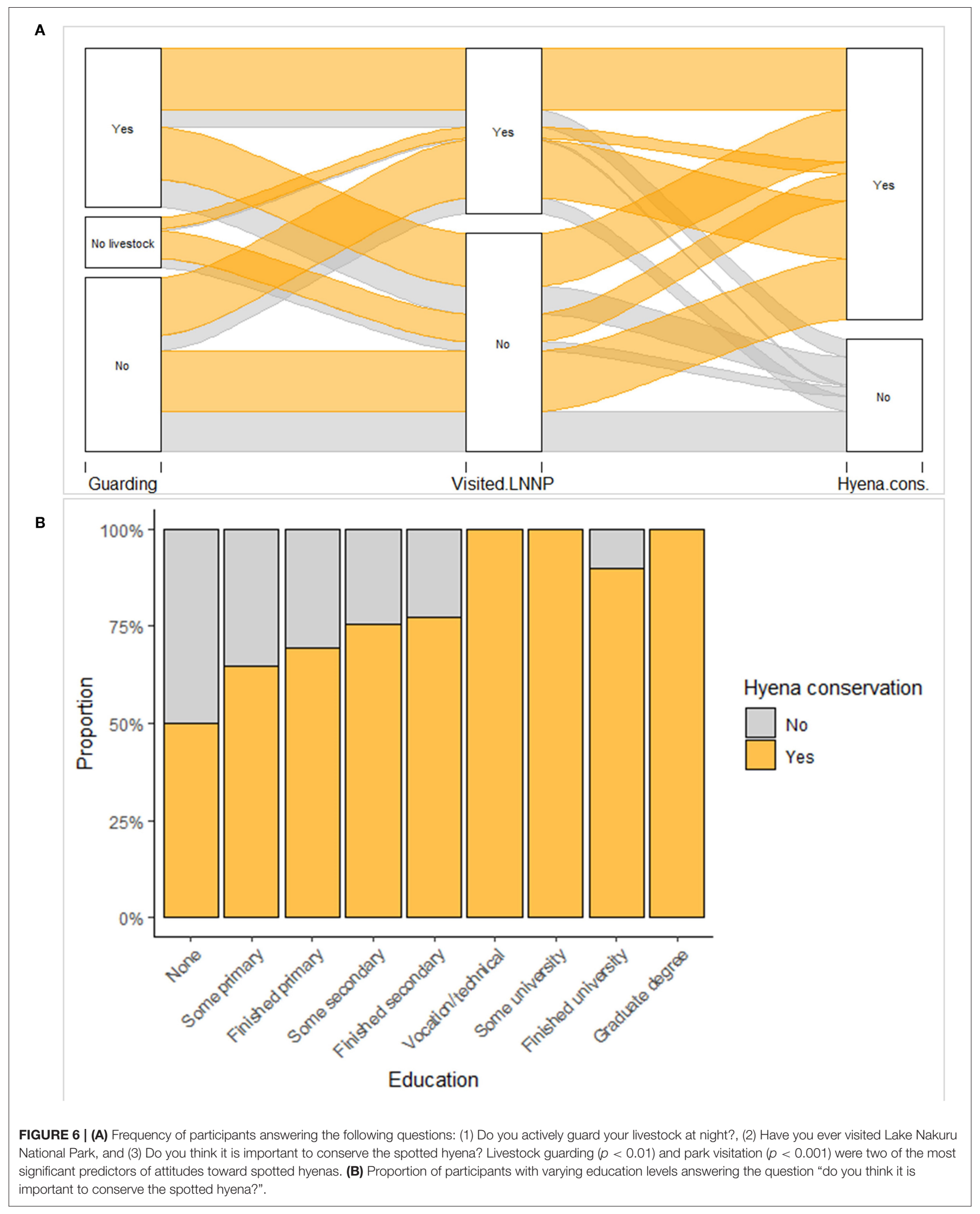


carnivores could be more likely to use as habitat (e.g., Kolowksi and Holekamp, 2006; Thorn et al., 2012; Broekhuis et al., 2017).

Road density, meanwhile, was positively correlated with both verified and perceived conflict. This could be because where there are people, there are more roads, and in this region human population density is increasing due to a boom in immigration (Were et al., 2013). Because wildlife in this densely developed area are likely more nocturnal (Gaynor et al., 2018), people are likely experiencing carnivore conflicts at night near their homes (Ugarte et al., 2019), rather than during the day while animals are out to pasture in open or less road-dense areas. However, there is also broader literature showing that isolation of people from nocturnal animal activity may reduce conflict (e.g., Carter et al., 2012b), so further research is needed in this area. As we consider carnivore management in increasingly human-dominated landscapes, it is important to take into account how human activity and infrastructure is correlated with concentrations of conflict risk (e.g., Said et al., 2016), and translate these findings into thoughtful conservation-friendly infrastructure development.

While many people in our study reported using tools for nighttime livestock protection, livestock guarding was not a significant predictor of spatial patterns of perceived conflict. This aligns with our understanding that many HCC interventions are implemented without evidence of their effectiveness (MoreiraArce et al., 2018). However, people's beliefs about two factors-wild prey availability and carnivore-related threats to children-correlated with spatial patterns of perceived conflict that was reported despite guarding efforts. Similarly, spatial trends of perceived conflict and their correlates were evident for regions where people still perceived livestock depredations despite their positive attitudes toward carnivores. These analyses can help us to understand not only what might compel people to overreport conflict, but also which regions to target for locally-specific drivers of conflict.

\section{Trends in Verified Conflict}

Verified human-carnivore conflict reports in Nakuru County exhibited several trends that ran counter to our predictions and may be a result of anthropogenic ecosystem change. For instance, seasonality was not a strong predictor of verified conflict, though the verified reports skewed slightly toward the dry season. This runs counter to a common belief that wildlife are able to disperse more widely during the rainy season in arid ecosystems (Koziarski et al., 2016), but correlates with reports of wildlife leaving fenced protected areas more frequently in the dry season (Kesch et al., 2015; Wilkinson et al., 2021).

Despite being one of the most abundant carnivore species in the region, black-backed jackals were not reported in the verified dataset. This result matched with the perceived data regarding participants' fears of carnivore-related threats to children on their way to school; jackals were the species least likely to be feared by participants. However, jackals are known to prey on vulnerable young livestock (Kamler et al., 2012), and have been seen doing so in this particular study area (author observation). Additionally, verified reports attributed to serval increased while leopard reports decreased. Because of the rapid development and deforestation in the region over the past decade (Mubea and Menz, 2012), it is possible that this trend is evidence of mesopredator release following declines in leopard populations (Prugh et al., 2009). While reporting bias and understaffing may have resulted in a limited verified conflict dataset from which to draw conclusions, the dataset's length of time and consistency of collection likely overcame these biases when assessing these basic trends. Future research on HCC should look more deeply into ecological and social drivers of observed trends in verified reports to better inform conflict management and to provide insight into broader ecological trends in conflict-prone regions.

\section{Predictors of Perceived Conflict, Perceived Risk, and Attitudes}

Visitation to Lake Nakuru National Park was one of the strongest predictors of lower perceived conflict, less perceived risk, and positive attitudes toward carnivores. This held true even if the participant themselves hadn't visited but their child had. Educational efforts regarding conservation are known for being frequently touted, but rarely evaluated (Tomicevic et al., 2010). Our results could be an important data point regarding the effectiveness of environmental education in communities dealing with conflict. This result is especially surprising given the intense immigration into the region; it is possible that visitation to the national park can drive formation of a "sense of place"or connection to the environment in this region-and thus a stronger connection to wildlife. Sense of place (Hausmann et al., 2016) is solidified when people are young, which could be influencing the strength of the effect of children's national park visitation. Importantly, domestic tourism is not only important for connecting people with their protected areas, but is also one of many ways to address sub-Saharan Africa's over-reliance on international tourism which is subject to collapse during stochastic events such as COVID-19 (Lindsey et al., 2020). Kenya and other countries with similar reliance on tourism revenue could take these results as another benefit to enhancing their domestic tourism infrastructure to make protected areas more accessible to its citizens and particularly the local communities living near conservation areas (Sindiga, 1996; Okello et al., 2012).

While national park visitation could be influencing people's wildlife-related knowledge, formal education level was arguably the strongest predictor in our perceived conflict and attitude models. Our results show that having any amount of primary school education made a participant more likely to have positive views toward carnivores, and less likely to report perceived risk of livestock conflict. This aligns with other studies that have found education levels to be linked with positive attitudes and reduced risk perceptions regarding carnivores (Holmern et al., 2007; Dressel et al., 2014; Knopff et al., 2016; Koziarski et al., 2016). However, nearly $15 \%$ of our participants reported having received no schooling, which could be due to the lack of compulsory education during the schooling years of older participants (whereas now basic education in Kenya is compulsory and free), or in part due to school accessibility and transportation. In this region, some primary and secondary students are known to walk long distances to attend school (author observation). Education is an avenue for learning about the environment and perhaps changing attitudes toward wildlife (Tomicevic et al., 2010). The strong link we see between education and 
perceptions of carnivores and conflict may be an additional compelling argument for increasing access to basic education and conservation awareness programs where communities are sharing landscapes with carnivores.

Lastly, across education levels and park visitation rates, gender played an important role in predicting the nature of perceptions and attitudes. For instance, women were more likely to voice that money from ecotourism was an important reason to conserve spotted hyenas. This could be because in many parts of sub-Saharan Africa, women serve as crucial links from the community to the national parks and reserves through selling handmade crafts and food to tourists (Twining-Ward et al., 2018). In fact, women participants in this study often enthusiastically reported they would "benefit from wildlife if we were able to sell our [goods] to tourists," even if they hadn't yet had the opportunity to do so. Notably, women also reported fewer perceived conflicts than men (i.e., less likely to overreport, and/or differences in daily experiences; Gore and Kahler, 2012), which could further reflect their importance as a specific demographic to target for co-created conflict solutions.

\section{CONCLUSION}

Human-carnivore conflict is a global challenge that is influenced by synergistic ecological and social dynamics. This study quantified differences in verified and perceived conflict and identified predictors of those differences. Despite the high levels of perceived conflict reported by interviewees, participants had largely positive attitudes toward carnivore conservation, even though there has been increased immigration into the region and a considerable subset of our interviewees were not long-term residents. Previous research has shown that the longer a person resides in the area, the more positively they feel toward certain species of large carnivores (Mkonyi et al., 2017), but our findings demonstrate more nuance in this than originally thought.

We were able to explore complexity in patterns of conflict using spatial analyses to understand where verified and conflict datasets diverge, what socioecological factors might predict spatial patterning in conflict reports, and which correlates of perceived conflict are more important in particular local regions. Our results provide empirical evidence to reinforce the understanding that working with communities to explore these mismatches can promote socially just and sustainable management of human-carnivore conflicts (Redpath et al., 2013). Additionally, our findings highlight the fact that land subdivision, fragmentation, and fencing within the landscape should be addressed through inclusive spatial planning to avoid exacerbating conflicts while supporting conservation measures and local community livelihoods (Said et al., 2016). Future research on human-carnivore conflict in developing landscapes should recognize that incorporating participatory methods and social science with ecological data is critical for inclusivity in addressing longstanding conservation conflicts and preventing the emergence of new ones (Weldemichel and Lein, 2019).

\section{DATA AVAILABILITY STATEMENT}

The raw data supporting the conclusions of this article will be made available by the authors, without undue reservation.

\section{ETHICS STATEMENT}

The studies involving human participants were reviewed and approved under UC Berkeley OPHS/CPHS Protocol \#201802-10731. Verbal informed consent was retrieved according to the requirements of the institution and protocol. Written informed consent for participation was not required for this study in accordance with the national legislation and the institutional requirements.

\section{AUTHOR CONTRIBUTIONS}

CW: conceptualization, methodology, formal analysis, investigation, writing-original draft, writing-review \& editing, visualization, supervision, funding acquisition, and project administration. JB: conceptualization, writingreview, and editing. AB: methodology, project administration, writing-review, and editing. MK: conceptualization, validation, writing-review and editing, and visualization. All authors contributed to the article and approved the submitted version.

\section{FUNDING}

This work was carried out under UC Berkeley OPHS/CPHS Protocol \#2018-02-10731. This work was supported by the National Geographic Society (GRANT EC 339C-18) and the Rocca Fellowship. CW was funded by a National Science Foundation Graduate Research Fellowship at the time of this study.

\section{ACKNOWLEDGMENTS}

We thank the Kenya Wildlife Service and the National Commission for Science, Technology, and Innovation for permission to conduct this research (NACOSTI/P/18/83301/21274, KWS/BRM/5001). We thank G. Osuka, C. Chepngeno, K. Combes, H. Jerotich, B. Limo, H. Ole Sanoe, E. Kiarie, E. Wangechi, C. Kisich, and KWS rangers for their valuable expertise and logistical support. We thank the Kelly Lab and Brashares Group for helpful comments and feedback throughout analysis and writing. We also thank S. Amaro-Gonzalez, C. Choi, H. DeMarco, U. Harwood, J. Karalis, A. Luneng-Solli, and K. Wooley for their digitization efforts.

\section{SUPPLEMENTARY MATERIAL}

The Supplementary Material for this article can be found online at: https://www.frontiersin.org/articles/10.3389/fcosc. 2021.681769/full\#supplementary-material

Supplementary Figure 1 | Proportion of verified conflict reports seasonally over time. Dotted line demarcates $50 \%$ of reports. 


\section{REFERENCES}

Akama, J. S., Lant, C. L., and Burnett, G. W. (1995). Conflicting attitudes toward wildlife conservation programs in Kenya. Soc. Nat. Res. 8, 133-144. doi: 10.1080/08941929509380907

Bartzke, G. S., Ogutu, J. O., Mukhopadhyay, S., Mtui, D., Dublin, H. T., and Piepho, H.-P. (2018). Rainfall trends and variation in the Maasai Mara ecosystem and their implications for animal population and biodiversity dynamics. PLOS ONE 13:e0202814. doi: 10.1371/journal.pone.0202814

Barua, M., Bhagwat, S. A., and Jadhav, S. (2013). The hidden dimensions of humanwildlife conflict: Health impacts, opportunity and transaction costs. Biol. Cons. 157, 309-316. doi: 10.1016/j.biocon.2012.07.014

Blankertz, L. (1998). The value and practicality of deliberate sampling for heterogeneity: A critical multiplist perspective. Amer. J. Eval. 19, 307-324. doi: 10.1177/109821409801900304

Broekhuis, F., Cushman, S. A., and Elliot, N. B. (2017). Identification of humancarnivore conflict hotspots to prioritize mitigation efforts. Ecol. Evol. 7, 10630-10639. doi: 10.1002/ece3.3565

Brown, G. (2012). Public participation GIS (PPGIS) for regional and environmental planning: reflections on a decade of empirical research. URISA 25, 5-16.

Brunsdon, C., Fotheringham, A. S., and Charlton, M. E. (1996). Geographically weighted regression: A method for exploring spatial nonstationarity. Geog. Analys. 28, 281-297. doi: 10.1111/j.1538-4632.1996.tb00936.x

Bruskotter, J. T., Vucetich, J. A., Manfredo, M. J., Karns, G. R., Wolf, C., Ard, K., et al. (2017). Modernization, risk, and conservation of the world's largest carnivores. Bioscience 67, 647-655. doi: 10.1093/biosci/bix049

Bruskotter, J. T., and Wilson, R. S. (2014). Determining where the wild things will be: Using psychological theory to find tolerance for large carnivores. Cons. Lett. 7, 158-165. doi: 10.1111/conl.12072

Burnham, K. P., and Anderson, D. R. (2002). Model Selection and Inference: A Practical Information-Theoretic Approach, 2nd Ed. New York, NY: Springer.

Carter, N. H., Krestha, B. K., Karki, J. B., Pradhan, N. M. B., and Liu, J. (2012b). Coexistence between wildlife and humans at fine spatial scales. PNAS 38, 15360-15365. doi: 10.1073/pnas.1210490109

Carter, N. H., Riley, S. J., and Liu, J. (2012a). Utility of a psychological framework for carnivore conservation. Oryx 46, 525-535. doi: $10.1017 /$ S0030605312000245

Dickman, A. J. (2010). Complexities of conflict: The importance of considering social factors for effectively resolving human-wildlife conflict: Social factors affecting human-wildlife conflict resolution. Anim. Conserv. 13, 458-466. doi: 10.1111/j.1469-1795.2010.00368.x

Dickman, A. J., Hazzah, L., Carbone, C., and Durant, S. M. (2014). Carnivores, culture and 'contagious conflict': Multiple factors influence perceived problems with carnivores in Tanzania's Ruaha landscape. Biol. Cons. 178, 19-27. doi: 10.1016/j.biocon.2014.07.011

Dickman, A. J., Macdonald, E. A., and Macdonald, D. W. (2011). A review of financial instruments to pay for predator conservation and encourage humancarnivore coexistence. PNAS 106, 13937-13944. doi: 10.1073/pnas.1012972108

Dorresteijn, I., Hanspach, J., Kecskes, A., Latkova, H., Mezey, Z., Sugar, S., et al. (2014). Human-carnivore coexistence in a traditional rural landscape. Land. Ecol. 29, 1145-1155. doi: 10.1007/s10980-014-0048-5

Dressel, S., Sandstrom, C., and Ericsson, G. (2014). A meta-analysis of studies on attitudes toward bears and wolves across Europe 1976-2012. Cons. Biol. 29, 565-574. doi: 10.1111/cobi.12420

Easterday, K., Paulson, T., DasMohapatra, P., Alagona, P., Feirer, S., and Kelly, M. (2018). From the field to the cloud: A review of three approaches to sharing historical data from field stations using principles from data science. Front. Environ. Sci. 6:88. doi: 10.3389/fenvs.2018.00088

Eklund, A., Flykt, A., Frank, J., and Johansson, M. (2020). Animal owners' appraisal of large carnivore presence and use of interventions to prevent carnivore attacks on domestic animals in Sweden. Eur. J. Wild. Res. 66:31. doi: 10.1007/s10344-020-1369-0

Espinosa, S., and Jacobson, S. K. (2012). Human-wildlife conflict and environmental education: Evaluating a community program to protect the Andean bear in Ecuador. J. Environ. Educ. 43, 55-65. doi: $10.1080 / 00958964.2011 .579642$
Gaynor, K. M., Hojnowski, C., Carter, N. H., and Brashares, J. S. (2018). The influence of human disturbance on wildlife nocturnality. Science 360, 1232-1235. doi: 10.1126/science.aar7121

Glickman, S. E. (1995). The spotted hyena from Aristotle to the Lion King: Reputation is everything. Soc. Res. 62, 501-537. Available online at: https:// www.jstor.org/stable/40971108

Gore, M. L., and Kahler, J. S. (2012). Gendered risk perceptions associated with human-wildlife conflict: Implications for participatory conservation. PLoS ONE 7:e32901. doi: 10.1371/journal.pone.0032901

Gray, S. M., Booher, C. R., Elliott, K. C., Kramer, D. B., Waller, J. C., Millspaugh, J., et al. (2020). Research-implementation gap limits the actionability of human-carnivore conflict studies in East Africa. Anim. Cons. 23, 7-17. doi: $10.1111 /$ acv. 12520

Hausmann, A., Slotow, R., Burns, J. K., and Di Minin, E. (2016). The ecosystem service of sense of place: Benefits for human well-being and biodiversity conservation. Environ. Cons. 43, 117-127. doi: 10.1017/S0376892915000314

Hemson, G., Maclennan, S., Mills, G., Johnson, P., and Macdonald, D. (2009). Community, lions, livestock, and money: A spatial and social analysis of attitudes to wildlife and conservation value of tourism in a human-carnivore conflict in Botswana. Biol. Cons. 142, 2718-2725. doi: 10.1016/j.biocon.2009.06.024

Holmern, T., Nyahongo, J., and Roskaft, E. (2007). Livestock loss caused by predators outside the Serengeti National Park, Tanzania. Biol. Cons. 135, 518-526. doi: 10.1016/j.biocon.2006.10.049

Hosmer, D. W., and Lemeshow, S. (Eds.). (2000). Applied Logistic Regression. New York, NY: John Wiley and Sons.

Kamler, J. F., Klare, U., and Macdonald, D. W. (2012). Seasonal diet and prey selection of black-backed jackals on a small-livestock farm in South Africa. Afr. J. Ecol. 50, 299-307. doi: 10.1111/j.1365-2028.2012.01324.x

Kassilly, F. N., Tsingalia, H. M., and Gossow, H. (2008). Mitigating human-wildlife conflicts through wildlife fencing: A Kenyan case study. Wildl. Biol. Pract.. 4, 30-38. doi: 10.2461/wbp.2008.4.3

Kellert, S. R. (1985). Public perceptions of predators, particularly the wolf and coyote. Biol. Cons. 31, 167-189. doi: 10.1016/0006-3207(85)90047-3

Kenya National Bureau of Statistics (2019). 2019 Kenya Population and Housing Census Volume II: Distribution of Population by Administrative Units. Kenya National Bureau of Statistics.

Kesch, M. K., Bauer, D. T., and Loveridge, A. J. (2015). Break on through to the other side: The effectiveness of game fencing to mitigate human-wildlife conflict. Afr. J. Wild. Res. 45, 76-87. doi: 10.3957/056.045.0109

Khumalo, K. E., and Yung, L. A. (2015). Women, human-wildlife conflict, and CBNRM: Hidden impacts and vulnerabilities in Kwandu Conservancy, Namibia. Cons. Soc. 13, 232-243. doi: 10.4103/0972-4923.170395

Knopff, A. A., Knopff, K. H., and Cassady, S.t., Clair, C. (2016). Tolerance for cougars diminished by high perception of risk. Ecol. Soc. 21:33. doi: 10.5751/ES-08933-210433

Kolowksi, J. M., and Holekamp, K. E. (2006). Spatial, temporal, and physical characteristics of livestock depredations by large carnivores along a Kenyan reserve border. Biol. Conserv. 128, 529-541. doi: 10.1016/j.biocon.2005.10.021

Koziarski, A., Kissui, B., and Kiffner, C. (2016). Patterns and correlates of perceived conflict between humans and large carnivores in northern Tanzania. Biol. Cons. 199, 1-50. doi: 10.1016/j.biocon.2016.04.029

Lindsey, P., Allan, J., Brehony, P., Dickman, A., Robson, A., Begg, C., et al. (2020). Conserving Africa's wildlife and wildlands through the COVID-19 crisis and beyond. Nat. Ecol. Evol. 4, 1300-1310. doi: 10.1038/s41559-020-1275-6

Lischka, S. A., Teel, T. L., Johnson, H. E., Reed, S. E., Breck, S., Don Carlos, A., et al. (2018). A conceptual model for the integration of social and ecological information to understand human-wildlife interactions. Biol. Cons. 225, 80-87. doi: 10.1016/j.biocon.2018.06.020

Lozano, J., Olszańska, A., Morales-Reyes, Z., Castro, A. A., Malo, A. F., Moleón, M., et al. (2019). Human-carnivore relations: A systematic review. Biol. Cons. 237, 480-492. doi: 10.1016/j.biocon.2019.07.002

McInturff, A., Xu, W., Wilkinson, C. E., Dejid, N., and Brashares, J. S. (2020). Fence ecology: Frameworks for understanding the ecological effects of fences. BioScience 70, 971-985. doi: 10.1093/biosci/biaa103

Megaze, A., Balakrishnan, M., and Belay, G. (2017). Human-wildlife conflict and attitude of local people towards conservation of wildlife 
in Chebera Churchura National Park, Ethiopia. Afr. Zool.. 52, 1-8. doi: 10.1080/15627020.2016.1254063

Meguro, T., and Inoue, M. (2011). Conservation goals betrayed by the uses of wildlife benefits in community-based conservation: The case of Kimana Sanctuary in southern Kenya. Hum. Dim. Wild. 16, 30-44. doi: 10.1080/10871209.2011.531516

Melzheimer, J., Heinrich, S. K., Wasiolka, B., Mueller, R., Thalwitzer, S., Palmegiani, I., et al. (2020). Communication hubs of an asocial cat are the source of a human-carnivore conflict and key to its solution. PNAS 117, 33325-33333. doi: 10.1073/pnas.2002487117

Miller, J. R. B. (2015). Mapping attack hotspots to mitigate human-carnivore conflict: Approaches and applications of spatial predation risk modeling. Biodivers. Cons. 24, 2887-2911. doi: 10.1007/s10531-015-0993-6

Miller, J. R. B., and Schmitz, O. J. (2019). Landscape of fear and humanpredator coexistence: Applying spatial predator-prey interaction theory to understand and reduce carnivore-livestock conflict. Biol. Cons. 236, 464-473. doi: 10.1016/j.biocon.2019.06.009

Mkonyi, F. J., Estes, A. B., Msuha, M. J., Lichtenfeld, L. L., and Durant, S. M. (2017). Local attitudes and perceptions toward large carnivores in a humandominated landscape of northern Tanzania. Hum. Dim. of Wild. 22, 314-330. doi: 10.1080/10871209.2017.1323356

Moreira-Arce, D., Ugarte, C. S., Zorondo-Rodriguez, F., and Simonetti, J. A. (2018). Management tools to reduce carnivore-livestock conflicts: current gap and future challenges. Bio One 71, 389-394. doi: 10.1016/j.rama.2018.02.005

Mubea, K., and Menz, G. (2012). Monitoring land-use change in Nakuru Kenya using multi-sensor satellite data. Adv. Rem. Sens. 1, 74-84. doi: 10.4236/ars.2012.13008

Muhly, T. B., and Musiani, M. (2009). Livestock depredations by wolves and the ranching economy in the northwestern U.S. Ecol. Econ.. 68, 2439-2450. doi: 10.1016/j.ecolecon.2009.04.008

Ogra, M. V. (2008). Human-wildlife conflict and gender in protected area borderlands: A case study of costs, perceptions, and vulnerabilities from Uttarakhand (Uttaranchal), India. Geoforum 39, 1408-1422. doi: 10.1016/j.geoforum.2007.12.004

Ogutu, J. O., Kuloba, B., Piepho, H., and Kanga, E. (2017). Wildlife population dynamics in human-dominated landscapes under communitybased conservation: The example of Nakuru wildlife conservancy, Kenya. PLoS ONE 12:169730. doi: 10.1371/journal.pone.0169730

Okello, M. M., Kenana, L., and Kieti, D. (2012). Factors influencing domestic tourism for urban and semiurban populations around Nairobi National Park, Kenya. Tour. Analys. 17, 79-89. doi: 10.3727/108354212X13330406124214

Pearce, J., and Ferrier, S. (2000). Evaluating the predictive performance of habitat models developed using logistic regression. Ecol. Modell.. 133, 225-245. doi: 10.1016/S0304-3800(00)00322-7

Pfeiffer, J. M., and Butz, R. J. (2005). Assessing the cultural and ecological variation in ethnobiological research: the importance of gender. J. Ethnobiol. 25, 240-278. doi: 10.2993/0278-0771(2005)25[240:ACAEVI]2.0.CO;2

Prugh, L.R., Stoner, C. J., Epps, C. W., Bean, W. T., Ripple, W. J., Laliberte, A. S., et al. (2009). The rise of the mesopredator. Bio. Sci. 59, 779-791. doi: 10.1525/bio.2009.59.9.9

R Core Team (2018). R: A Language and Environment for Statistical Computing. Vienna: R Foundation for Statistical Computing.

Redpath, S. M., Bhatia, S., and Young, J. (2015). Tilting at wildlife: reconsidering human-wildlife conflict. Oryx 49, 222-225. doi: 10.1017/S0030605314000799

Redpath, S. M., Young, J., Evely, A., Adams, W. M., Sutherland, W. J., Whitehouse, A., et al. (2013). Understanding and managing conservation conflicts. Trends Ecol. Evol.. 28, 100-109. doi: 10.1016/j.tree.2012.08.021

Ripple, W. J., Estes, J. A., Beschta, R. L., Wilmers, C. C., Ritchie, E. G., Hebblewhite, M., et al. (2014). Status and ecological effects of the world's largest carnivores. Science 33:1241484. doi: 10.1126/science.1241484

Rust, N. A., Whitehouse-Tedd, K. M., and MacMillan, D. C. (2013). Perceived efficacy of livestock-guarding dogs in South Africa: Implications for cheetah conservation. Wild. Soc. Bul. 37, 690-697. doi: 10.1002/wsb.352

Said, M. Y., Ogutu, J. O., Kifugo, S. C., Makui, O., Reid, R. S., and de Leeuw, J. (2016). Effects of extreme land fragmentation on wildlife and livestock population abundance and distribution. J. Nat. Cons. 34, 151-164. doi: 10.1016/j.jnc.2016.10.005

Siex, K. S., and Struhsaker, T. T. (1999). Colobus monkeys and coconuts: A study of perceived human-wildlife conflicts. J. Appl. Ecol. 36, 1009-1020. doi: 10.1046/j.1365-2664.1999.00455.x
Sindiga, I. (1996). Domestic tourism in Kenya. Ann Tourism Res. 23, 19-31. doi: 10.1016/0160-7383(95)00040-2

Tessema, M. E., Lilieholm, R. J., Ashenafi, Z. T., and Leader-Williams, N. (2010). Community attitudes toward wildlife and protected areas in Ethiopia. Soc. Nat. Res. 23, 489-506. doi: 10.1080/08941920903177867

Thorn, M., Green, M., Dalerum, F., Bateman, P. W., and Scott, D. M. (2012). What drives human-carnivore conflict in the North West Province of South Africa? Biol. Cons. 150, 23-32. doi: 10.1016/j.biocon.2012.02.017

Tomicevic, J., Shannon, M. A., and Milovanovic, M. (2010). Socio-economic impactso $\mathrm{n}$ the attitudes towards conservation of natural resources: Case study from Serbia. Forest Pol. Econ. 12, 157-162. doi: 10.1016/j.forpol.2009.09.006

Treves, A., and Karanth, K. U. (2003). Human-carnivore conflict and perspectives on carnivore management worldwide. Cons. Biol. 17, 1491-1499. doi: 10.1111/j.1523-1739.2003.00059.x

Treves, A., Wallace, R. B., and White, S. (2009). Participatory planning of interventions to mitigate human-wildlife conflicts. Cons. Biol. 23, 1577-1587. doi: 10.1111/j.1523-1739.2009.01242.x

Twining-Ward, L., Li, W., Bhammar, H., and Wright, E. (2018). Supporting Sustainable Livelihoods through Wildlife Tourism. Washington, DC: Tourism for Development; World Bank.

Ugarte, C. S., Moreira-Arce, D., and Simonetti, J. A. (2019). Ecological attributes of carnivore-livestock conflict. Front. Ecol. Evol. 7:433. doi: $10.3389 /$ fevo.2019.00433

USDA Animal and Plant Health Inspection Service (2020). USDA Wildlife Services to Use \$1.3 M to Implement, Evaluate Nonlethal Predator Management Tools. Available online at: https://content.govdelivery.com/accounts/USDAAPHIS/ bulletins/2869ala (accessed February 26, 2021).

van Eeden, L. M., Eklund, A., Miller, J. R. B., López-Bao, J. V., Chapron, G., Cejtin, M. R., et al. (2018). Carnivore conservation needs evidence-based livestock protection. PloS Biol. 16:e2005577. doi: 10.1371/journal.pbio.2005577

Waylen, K. A., McGowan, P. J. K., and Milner-Gulland, E. J. (2009). Ecotourism positively effects awareness and attitudes but not conservation behaviours: a case study in Grande Riviere, Trinidad. Oryx 43:343-351. doi: 10.1017/S0030605309000064

Weldemichel, T. G., and Lein, H. (2019). 'Fencing is our last stronghold before we lose it all.' A political ecology of fencing around the Maasai Mara National Reserve, Kenya. Land Use Pol. 87:104075. doi: 10.1016/j.landusepol.2019.104075

Were, K. O., Dick, Ø. B., and Singh, B. R. (2013). Remotely sensing the spatial and temporal land cover changes in Eastern Mau Forest Reserve and Lake Nakuru drainage basin, Kenya. Appl. Geog. 41, 75-86. doi: 10.1016/j.apgeog.2013.03.017

White, R. M., Fischer, A., Marshall, K., Travis, J. M. J., Webb, T. J., di Falco, S., et al. (2009). Developing an integrated conceptual framework to understand biodiversity conflicts. Land Use Pol. 26, 242-253. doi: 10.1016/j.landusepol.2008.03.005

Wilkinson, C. E., McInturff, A., Miller, J. R. B., Yovovich, V., Gaynor, K. M., Calhoun, K., et al. (2020). An ecological framework for contextualizing carnivore-livestock conflict. Cons. Biol. 34, 854-867. doi: 10.1111/cobi. 13469

Wilkinson, C. E., McInturff, A. M., Kelly, M., and Brashares, S. (2021). Quantifying wildlife responses to conservation fencing in East Africa. Biol. Conserv. 256:109071. doi: 10.1016/j.biocon.2021. 109071

Young, J. C., Marzano, M., White, R. M., McCracken, D. I., Redpath, S. M., Carss, D. N., et al. (2010). The emergence of biodiversity conflicts from biodiversity impacts: characteristics and management strategies. Biodiver. Conserv. 19, 3973-3990. doi: 10.1007/s10531-0109941-7

Conflict of Interest: The authors declare that the research was conducted in the absence of any commercial or financial relationships that could be construed as a potential conflict of interest.

Copyright (C) 2021 Wilkinson, Brashares, Bett and Kelly. This is an open-access article distributed under the terms of the Creative Commons Attribution License (CC BY). The use, distribution or reproduction in other forums is permitted, provided the original author(s) and the copyright owner(s) are credited and that the original publication in this journal is cited, in accordance with accepted academic practice. No use, distribution or reproduction is permitted which does not comply with these terms. 